\title{
Research on Social Work of Community Parenting Education Fuyu Du ${ }^{1, a}$ \\ ${ }^{1}$ Xinyu University, Xinyu, Jiangxi, 338004 \\ a email
}

\author{
Keywords: Paternity, Education, Social Work, Community
}

\begin{abstract}
With the development of society, China's increasing emphasis on early childhood family education, family and school for their children's education plays an important role, but the growth of children and families in addition to school education, is also inseparable from society, can not be separated community life, thus proposed to carry out research community parenting method of social work, in order to compensate for the lack of family education and school education, discusses the feasibility study social work community parenting undertaken to clarify the social work community Parenting Education to carry out the form, and describes the organization of community parenting program.
\end{abstract}

\section{Introduction}

With the improvement of social development, living conditions, early childhood education parents much attention, but not whether they are newly married couples to have children, or have children in nursery raising of parents, or being the second child of the family, have a small nurture the child's expectations. However, the investigation by the presence of many families' educational concept, the outdated", "a lack of educational resources, insufficient educational capacity ";" pursue supreme authority, parenting fuzzy rules "and other issues.

In the 20th century, as a new model of family parenting education has been proposed. It broke the traditional education to parents as the center of family education style, stressed parents, children achieve equality on the basis of interaction between parents and children continue to progress in family education, shared growth so as to enhance parent-child relationship, to achieve educational purposes. In recent years, with economic development, the government increasing emphasis on social construction, in the form of purchase of social service organizations in the community to carry out parenting education social work service activities, can effectively help parents do the child's early education.

\section{Feasibility of Social Work Community Parenting Education}

Social Work specialization enhances the ability of the parent-child education. Central in the Sixth Plenary Session of the Sixteenth to make a "CPC Central Committee on building a socialist harmonious society a number of major issues" should be made to the construction of grand social work personnel, the development of the personnel were training, evaluation, use, encouraging content and other policy measures to promote the social and professional workforce specialization, social workers to follow the correct value criteria, based on reasonable social work theory, the use of professional work methods, carry out scientific community parent-child education.

Social work policies are to support parenting education activities undertaken. Central Organization Department, the Central Political and Law Commission, Ministry of Civil Affairs and other departments and mass organizations and 19 April 2012 issued a "social work professionals building long-term plan (2011-2020)", not only the training of personnel of social work, specialized personnel were planning, but also establishes the use of professionals, incentive safeguards for private nonprofits to provide social work services, Ministry of Civil Affairs and the Ministry of Finance in November 2012 issued a "Ministry of Civil Affairs, Ministry of Finance on government Purchasing the Social work service guidance, "to make a range of social work services, quantity, size and quality to meet the requirements of economic and social development, meet the people's 
individuality, diversity, and professional services needs to provide financial security.

Social work is an application of the strong social sciences, it has a working method when due under certain theoretical guidance because of something specific. Generally, it includes direct and indirect methods of social work. Direct methods of work have casework, social work administration group work, community work, indirect methods of work. Improve parenting effect of both family responsibility and social responsibility, to promote family harmony, communal harmony and social stability in the new situation of social development, is necessary to the introduction of parenting social work methods, make full use of social work ways you can play against, and treatment in developing parent-child education. Casework by providing individual have parenting needs of families parenting knowledge to help solve family problems, reduce family education pressure, mainly to provide the therapeutic services; Team work carried out group interaction, and with groups sharing experiences, play team advantage, each family in the group interaction each other, enhance parenting capacity, and promote the smooth functioning of family education, and promote the development of parent-child education; community work community family-oriented, in carrying out parenting education activities focus on creating a parent-child education atmosphere to promote parenting knowledge, promote parent-child education and family-oriented community, in order to better play the educational function of the family, the foundation for the healthy growth of children, are preventative services.

\section{The Form of Parenting Education in Community Social Work}

Parenting community development process in a variety of activities should be organized in the form, content, and diverse, varied forms, each form of activity has its own focus, the use of their own characteristics, the formation of complementary advantages. Various forms of activities both independent and associated with each other, can play a balanced and complementary role to enrich the connotation of parenting.

Parents have a hopeful, hope strong desire Cheng-feng, and I hope the healthy growth of children, the future become useful to society. But in real life, the basis of different cultures within the community of parents, some parents may very lack of knowledge of parenting, even if it is relatively high cultural level of the parents, this piece of parenting does not necessarily understand, learn some more education knowledge, not necessarily scientific use; some parents own experience and different growing family environment, education used incorrectly, such as forcing some parents to take child education, etc., the results are often counterproductive; some parents living conditions, long-term in the field, but also need to understand the parenting knowledge, children learn how to communicate with the outside, and with guardians to teach children. Therefore, to carry out systematic parenting seminars, teach parenting knowledge, skills, answer puzzled the minds of parents, parental education to improve attitudes and behavior are necessary.

Although the seminar can teach parenting knowledge systems, it can not interact well. Parental organized classroom has many advantages. Systematic, in a period of time, relatively fixed node at a time, in multiple systems taught knowledge of certain aspects, such as social Yushui loving home studio, for intimate tour Parental every Saturday afternoon or evening education courses in a semester finished intimate weekend tour packages; interactive, teaching process, the instructor at any time based teaching content and requirements, and parents to interact, discuss parenting skills; sharing, parental participation in lectures, have parenting experience, has achieved successful place, when it comes to topics in this area, you can come up with to share with you, so that other parents have learned to practice was a valuable experience; participation, lectures or after classes, will organize activities related to parent-child, parents and children together to participate closely with each other, the father (mother) son together to complete the activity, activity among children and parents continued physical contact, such as to help his mother quickly put on shoes, three legs, etc. these activities enhance the intimacy of parents and children, the child's intellectual development plays an important role.

Community parenting education activities are not necessarily limited to the indoors in the form of lectures and taught, as needed, to carry out parenting outdoor activities. After several indoor 
lectures for parents and children to better mobilize the enthusiasm of the class, the rich class content and form, you can choose suitable climate weekends to organize family activities outdoors. Site selection in the Community Cultural Square can be into a residential area, or to the park near the square and the like. Organizing outdoor activities, parenting education teacher informed in advance of the time and place of parents activities, told brought utensils and related considerations. Time to parent-child activities, parent-child should have well-prepared teachers with a curriculum, campaign materials, to activities, to guide children and parents conduct parent-child activities. Preparations for various activities have a different sense of family activities, sports classes, class talent show, fun game, expand the quality and the like. Participation in activities, children and parents play together, run, competition, Responder, attracted a lot of people watching, they cheer for the children from time to time to show cute children applauded. Outdoor family activities, flexible modes of teaching expand parenting beneficiary groups to enrich the cultural life of the community residents. Especially the parent-child performer and give children a stage show themselves. Most children now have the opportunity to learn a variety of conditions talent, but also the talent show, but also the desire to show themselves, organize parent-child outdoor performances, it provides a broad scope for more children, so that they enjoy the talent show, success and self-confidence, parent-child performances for the community to provide a family to appreciate each other, exchange and learning platform.

Community undertaken in parenting, we can not be satisfied with the effect of parent-child education, parent-child relations and even individual families will be a big problem, such as wayward children, just do not listen to adults; children always have a tendency to procrastinate, to do her What, always reluctant to be completed in time; some children are more unruly, always do some rules do not allow the "bad"; some children also partial eccentric personality, do not like the people around exchanges, etc., which lists only child growing when several issues, some parents are faced with these problems, like a lot of ways, various attempts are used, but for some reason, that did not have much effect, so the psychological irritability, education, the method may be more simple and crude, The results are less satisfactory. For children growing personality bias problem, sometimes parenting classes and activities to help is limited, then it is necessary to carry out targeted families in need of home visits, a comprehensive understanding of the child's birth family upbringing, education familiar with the action taken by the parents, careful analysis of the causes of child deviation depth understanding of the child's own unique personality, to work out a viable solution. Home visits are an important means of working teachers, teachers and children, parents bridge. Through home visits, teachers and parents can reach consensus on certain issues, to improve the educational methods of parents to promote the educational objectives. Thus, the implementation of the action loving home visits, parenting teachers to use professional knowledge and skills, there is confusion as to help families to solve the problems encountered in parenting and child-rearing for parents to provide scientific support.

\section{Social Work Organization of Community Parenting Education}

To guarantee the smooth development of community parenting education, parent-child education in the development of community before, during and after undertaken to carry out, must be carefully organized.

Prior Events Find community parenting needs. Before the development of community parenting education activities, families need to know whether there are aspects of parenting confused, what are the main confusion exists; conduct seminars or series of parent-child class, the first to understand the situation, in order to teach targeted, real family to clear up doubts, to parents provide effective help for healthy growth of children escort. Learn Community parental education needs through surveys can also learn to Kindergarten relevant teacher child behavior, or the formation of parenting micro-channel group, QQ group, in the group to the parents to understand parents parenting before asking all parents present in education confusion, of course, you can also have the opportunity to take advantage of opportunities to meet with parents, random interviews with details of family child education. 
Learn parenting community needs, we can begin designing parenting education programs. Three programs are generally required to contain the content, subject matter and purpose parenting education, parent-child education in the form and content of risk management and contingency plans. Theme should develop simple, people to see at a glance, the purpose behind the incidental described objective of the educational activities, the harvest will be achieved, such as access to scientific parenting skills; activities in the form of instructions are seminars, lectures or outdoor family activities etc., and a brief description of the contents; risk control is mainly to consider some safety factors, especially for outdoor activities, in order to prevent injury or respond to weather changes, to remind parents to bring relevant necessary protective tools, if they are weather changes, be prepared emergency measures.

After doing the program in educational activities three days ago posted poster, issued a notice in the micro-letters and other groups, recruited to participate in the activities of family members, to determine the number of participants, in order to make preparations in advance of the event. Methods title, main course content, course curriculum that is the importance of the benefit (such as master new parenting methods, training methods and techniques of child self-confidence, cultivate children's independence, sense of responsibility: General Matters notification should contain the following and skills, should be able to write content cause parents concern), instructors, teaching methods and features (new thinking parent-child training + experience activities if new teaching methods more attractive), teaching time and place, and contacts Information (contacts generally composed by the three assistant) Notes (Tip participant ready the necessary utensils), last write date and organizer. After notification, a good contact is responsible for the registration of persons enrolled in the course information.

When the event begins, teachers use simple language to explain the main content of the activities to parents, and to make the necessary requirements. The next educational activities to arouse interest in the idea of parents and children, teachers can make use of well-prepared material to attract children and their parents, so that we enter the state. Activities, the organizers should pay attention to guide parents observe the child's activities, and actively encourage children to complete the task, the child's respect for differences, to teach children to experience the learning process and methods. After the event, the organizers want to achieve the target level of inspection activities, summary activities, to the parents of home needs to be done to extend the activities of the job, and a brief summary of activities.

\section{References}

[1] Gu Hua, Zhang Jun. Use of community parenting resource optimization [J]. Early education • teaching and research. 2012, (1).

[2] Zhang Ganqun. Community Resources optimization Parenting [J]. Now science education General Education. 2013 (3).

[3] Wu Xiaoyan. Social work parenting intervention research [D]. Shaanxi. Northwest A\&F University . 2015. 4. 